\title{
Illuminating Neural Circuits: From Molecules to MRI
}

\author{
Jin Hyung Lee, ${ }^{1}$ Anatol C. Kreitzer, ${ }^{2}$ Annabelle C. Singer, ${ }^{3}$ and Nicholas D. Schiff ${ }^{4}$ \\ ${ }^{1}$ Stanford University, Stanford, California 94305, ${ }^{2}$ Gladstone Institute, San Francisco, California 94158, ${ }^{3}$ Georgia Institute of Technologyand Emory School \\ of Medicine, Atlanta, Georgia 30332, and ${ }^{4}$ Weill Medical College of Cornell University, New York, New York 10065
}

Neurological disease drives symptoms through pathological changes to circuit functions. Therefore, understanding circuit mechanisms that drive behavioral dysfunction is of critical importance for quantitative diagnosis and systematic treatment of neurological disease. Here, we describe key technologies that enable measurement and manipulation of neural activity and neural circuits. Applying these approaches led to the discovery of circuit mechanisms underlying pathological motor behavior, arousal regulation, and protein accumulation. Finally, we discuss how optogenetic functional magnetic resonance imaging reveals global scale circuit mechanisms, and how circuit manipulations could lead to new treatments of neurological diseases.

Key words: Alzheimer's disease; arousal; basal ganglia; gamma frequency; ofMRI; optogenetics

\section{Introduction}

Neurological diseases have traditionally been considered in the context of pathological, molecular changes. However, pathological changes drive neurological disease symptoms (behavior) through resulting circuit function changes. Therefore, for both quantitative diagnosis and accurate therapeutic intervention, understanding circuit mechanisms that drive behavioral outcome is critical. Very recent technological advances are starting to fundamentally change our ability to access this information.

Here, we will cover key state-of-the art technologies that enable distinct anatomical and functional aspects of brain circuits to be directly measured. These technologies are widely applicable to investigation of all neurological circuits. Furthermore, important circuit mechanisms and therapeutic approaches underlying Parkinson's disease, traumatic brain injury, and Alzheimer's disease (AD), which were revealed using novel technologies, will be discussed. Understanding the circuit mechanism role in neurological disease is a critical step in improved diagnosis and treatment of all neurological diseases.

In summary, we will introduce: (1) cutting-edge experimental approaches for visualizing and manipulating neural circuits; (2) novel circuit mechanisms; (3) role of circuit defects in neurological disease; and (4) highlighting therapeutic approaches aimed at manipulating circuit mechanisms. The goal is to better understand the role of neural circuits in normal brain function and how their impairment underlies neurological disease, and emerging ability to use this knowledge to develop therapeutics.

Received Sept. 7, 2017; revised Sept. 22, 2017; accepted Sept. 26, 2017.

A.C.S. owns shares of Cognito Therapeutics. The remaining authors declare no competing financial interests.

Correspondence should be addressed to Dr. Jin Hyung Lee, 318 Campus Drive, \#W300A, Stanford, CA 94305.

E-mail: ljinhy@stanford.edu.

DOI:10.1523/JNEUROSCI.2569-17.2017

Copyright $\odot 2017$ the authors $\quad 0270-6474 / 17 / 3710817-09 \$ 15.00 / 0$

\section{Optogenetic fMRI (ofMRI)}

Scientific questions, hurdles, and technology needs

One of the central questions of neurobiology is how large-scale brain network activity relates to behavior. Answers remain elusive. We face two main obstacles: (1) the brain is a complex network of heterogeneous neurons, requiring cellular level information to understand its function; and (2) the brain is protected by a thick skull, greatly complicating efforts to electrically or optically monitor the brain's activity. Even when electrodes or fibers are invasively introduced into the brain, its large volume and optical properties restrict measurements to local preselected regions. Therefore, despite groundbreaking developments that have greatly improved our ability to stimulate and monitor the brain, we can only measure brain function at polar ends of the spectrum. That is, we can either track individual neuronal activity in a preselected small brain region using microscopy or measure global brain function with millimeter spatial resolution using noninvasive tomographic imaging (e.g., MRI or PET). However, specific cell types within a brain network have unique contributions to behavioral output, and even a single neuron can make connections to large portions of the brain. To uncover brain function, we need measurements with the seemingly incompatible characteristics of cellular specificity, on the one hand, and whole-brain readout, on the other.

ofMRI

This challenge can in part be addressed by ofMRI. Optogenetics uses light for cell type-specific, millisecond-scale activity modulation. High-field fMRI is a noninvasive technology for imaging the neural activity in live subjects across the whole brain. ofMRI makes it possible to link specific cellular activities to global brain functions. We showed that excitatory cell-type-triggered fMRI responses could be measured in local and remote areas of the brain with temporal precision (Lee et al., 2010).

\section{Advanced ofMRI technology development}

As with any novel technology, additional development is necessary to bring ofMRI to its full potential. Based on our goal of 
visualizing global brain functions associated with specific cellular populations activated during behavior, we successfully developed a real-time ofMRI platform with robust motion correction and closed loop control. This platform enables overall image reconstruction and motion correction to be conducted in $12.8 \mathrm{~ms}$ (Fang and Lee, 2013), in contrast to $\sim 8 \mathrm{~s}$ without the parallel computation algorithms we developed. We make image reconstruction $>600$ times faster, and also developed a novel compressed sensing algorithm that improved spatial resolution by a factor of 6 , achieving $200 \times 200 \mu \mathrm{m}^{2}$ and $140 \times 140 \mu \mathrm{m}^{2}$ in plane resolution while covering the whole rat and mouse brain, respectively. This improved spatial resolution empowers cortical layer and subnuclei-specific imaging in ways not previously possible (Fang et al., 2016). In addition to developing software algorithms, we have also developed hardware to allow simultaneous electrophysiological recordings during ofMRI (e.g., MRIcompatible optrodes) (Duffy et al., 2015). We continue to push the technology toward real-time, feedback controlled, highspatial-resolution, and awake-behaving ofMRI with simultaneous electrophysiology. We are currently able to perform awake, nonbehaving ofMRI with robust, high-resolution signal detection in real time with simultaneous electrophysiology. The next major hurdle in the field is awake-behaving ofMRI, and this is one of our current research projects.

\section{Circuit mechanisms underlying motor behavior}

\section{Basal ganglia circuits in motor performance}

The basal ganglia are a set of subcortical nuclei involved in motivation, reinforcement, and automation of motor behavior. They have proven particularly amenable to modern recording and perturbation methods in systems neuroscience, as they consist of a small number of well-delineated nuclei interconnected by genetically defined cell types (Bolam et al., 2000). The striatum, a major input nucleus to the basal ganglia, consists largely of striatal projection neurons $(\mathrm{SPNs})$, with a minority $(<5 \%-10 \%)$ of interneurons. These projection neurons can be divided into two major classes: direct-pathway neurons (dSPNs), which project directly to basal ganglia output nuclei; and indirect-pathway neurons (iSPNs), which project indirectly to basal ganglia outputs, via the external globus pallidus (Smith et al., 1998). A classical model developed in the 1980s to explain the symptoms of extrapyramidal movement disorders predicted that dSPNs facilitate motor behavior, whereas iSPNs suppress motor behavior (Albin et al., 1989; DeLong, 1990). A series of papers describing celltype-specific lesions demonstrated findings consistent with this hypothesis (Drago et al., 1998; Sano et al., 2003; Durieux et al., 2009; Hikida et al., 2010), but until the advent of optogenetics, there was no temporally precise method for directly perturbing and testing the function of these circuits.

Within the last decade, the combination of specific Cre-driver lines, Cre-dependent viruses, and genetically encoded optogenetic and imaging probes has enabled a series of studies focused on the function of these distinct circuits. The first optogenetic study of basal ganglia circuitry used selective stimulation of dSPNs and iSPNs with channelrhodopsin-2 in awake freely moving mice to examine the behavioral effects of activating basal ganglia circuitry (Kravitz et al., 2010). As predicted by the classical model, activating the direct pathway facilitated movement, as evidenced by increased locomotion and decreased immobility, whereas activating the indirect pathway suppressed movement and mimicked a parkinsonian state, as evidenced by increased immobility, and strongly decreased locomotion. Many of the observed behavioral effects can be explained through cell- type-specific projections from basal ganglia output nuclei to the mesencephalic locomotor region (Roseberry et al., 2016). Activity in mesencephalic locomotor region glutamate neurons is highly predictive of the locomotor state, and their optogenetic activation is sufficient to drive locomotion with short latency. These neurons are innervated by basal ganglia output nuclei and bidirectionally controlled by dSPNs and iSPNs. Thus, a simple classical model prediction is borne out in the case of locomotor control.

However, a subsequent imaging study using calcium indicators to measure bulk activity in dSPNs or iSPNs during a motor behavior observed a result that seemed to contradict such a simple model of motor control: both dSPNs and iSPNs were active at the same time during movements to the contralateral side (Cui et al., 2013). We have observed similar results when measuring dSPN and iSPN activity during locomotor starts in the open field (Kravitz and A.C.K., unpublished data). Can these results be easily reconciled with the optogenetic experiments? If one imagines that all striatal neurons serve a similar function (e.g., locomotor control), then these results are perplexing. However, there is ample anatomical and functional evidence that striatal neurons integrate vast numbers of cortical and thalamic inputs and show complex activity patterns during motor behavior that cannot be easily categorized on the basis of subtype (Isomura et al., 2013). Using in vivo microendoscope-based imaging of striatal neurons in a simple foraging task, we observe broad heterogeneity within dSPN and iSPN populations, both in terms of their selectivity for movements and their responses to reward delivery or omission (Donahue and A.C.K., unpublished data). Indeed, interpreting such results requires a better understanding of basal ganglia function itself, which is a hotly debated topic. Potential functions include action selection, gain control, motor learning, and motor memory (for excellent reviews on this topic, see Redgrave et al., 1999; Desmurget and Turner, 2010; Ito and Doya, 2011; Hikosaka et al., 2014; Dudman and Krakauer, 2016). A recent imaging paper describes encoding of actions by ensembles of SPNs, independent of movement speed, indicating at least the possibility of orthogonal encoding of information to subserve both action selection and gain control (Klaus et al., 2017). As technology for large-scale cell-type-specific recordings, patterned illumination, and high-resolution behavior improves, we will be able to better map these functions onto distinct striatal regions and cell types, and link the activity patterns of striatal neurons to specific aspects of behavior.

\section{ofMRI of basal ganglia pathways}

Recent advances have enabled unprecedented control over the basal ganglia's direct and indirect pathways via optogenetic stimulation of D1- and D2-expressing MSNs. However, the influence of these neuronal populations on whole-brain circuitry was unclear. In a recent study (Lee et al., 2016), we used ofMRI to identify the activations and deactivations that occur across the brain during targeted stimulation of either population (Fig. 1). Responses evoked by D1- and D2-MSN stimulation were significantly different and typically opposite in polarity throughout the basal ganglia-thalamocortical circuit. Our results therefore provide the first experimental evidence that the direct and indirect pathways exert opposite influences on the activity of downstream brainwide regions. This has not been directly testable to date because previous technologies were limited to either local measurements (e.g., electrophysiology) during optogenetic perturbations or brainwide imaging without cell type-specific manipulations. The findings we present were empowered by our advanced optogenetic fMRI 
A

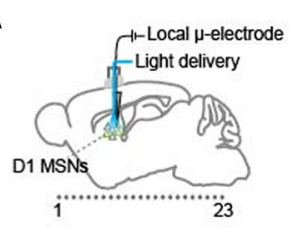

D

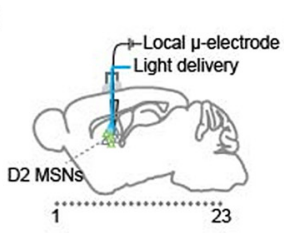

B

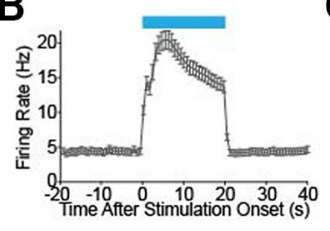

$E$



C

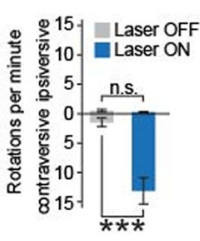

$F$

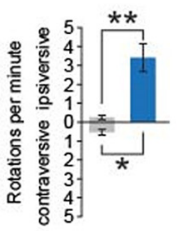

G

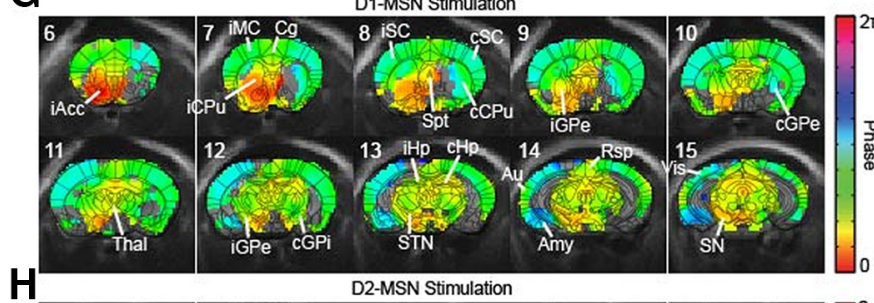

D1-MSN Stimulation

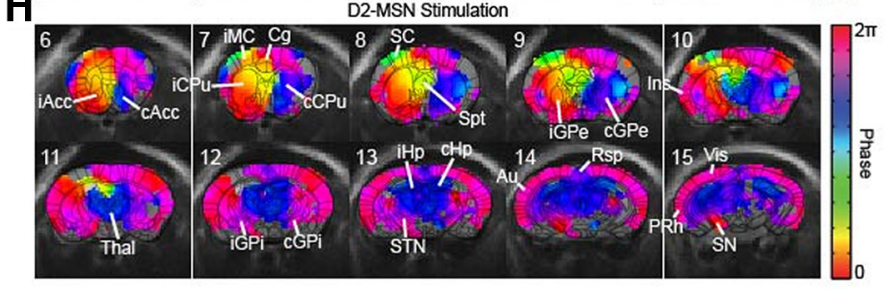

I

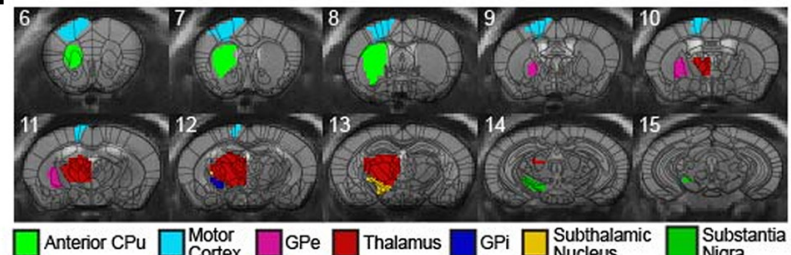

J $\square$ Anterior CPu $\square$ Cortex $\square$ GPe $\square$ Thalamus $\square$ GPi $\square_{\text {Nucleus }}^{\text {Sublalam }} \square$ Nigra


0.8 Motor Cortex, D2-MSN Stim.

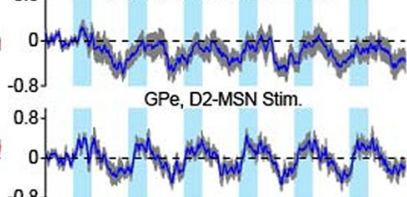

Thalamus, D2-MSN Stim

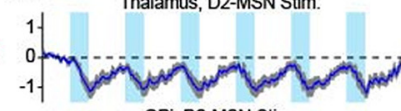

GPi, D1-MSN Stim.
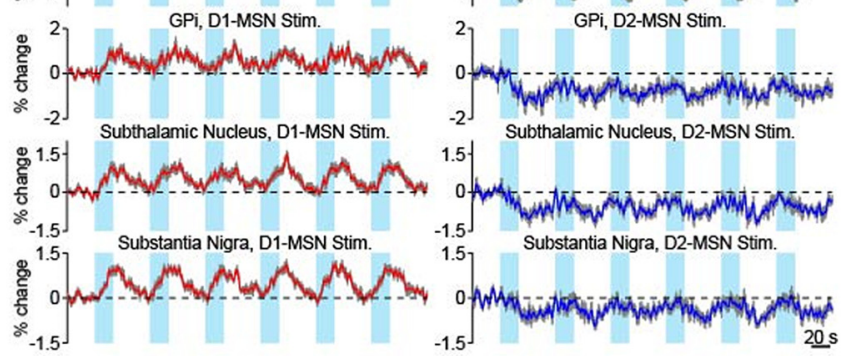

Figure 1. ofMRI with D1-, D2-MSN stimulations. $\boldsymbol{A}$, The $20 \mathrm{~Hz}$ D1-MSN stimulation in dorsomedial striatum results in increase of $(\boldsymbol{B})$ average firing rate $(n=120,100 \%)$ and $(\boldsymbol{C})$ number of contralateral rotations $(n=13) .{ }^{* *} p<0.001$. D, The $20 \mathrm{~Hz}$ D2-MSN stimulation in dorsomedial striatum results in increase of $(\boldsymbol{E})$ average firing rate $(n=15,93 \%)$ and $(\boldsymbol{F})$ number of ipsilateral rotations $(n=11) .{ }^{* *} p<0.005$. G, $\boldsymbol{H}$, Groupwise activation maps demonstrate the large-scale modulation of cortical and subcortical regions, including the basal ganglia, during D1- and D2-MSN stimulation. Significantly modulated voxels are color-coded according to their phase relative to six repeated cycles of $20 \mathrm{~s}, 20 \mathrm{~Hz}$ stimulations. $I$, Regions of interest, used for time series extraction in J. J, Average time series of active voxels during D1- and D2-MSN stimulation within each region of interest (left/red traces and right/blue traces, respectively). Values are mean \pm SEM across animals ( $n=13$ D1-MSN; $n=11$ D2-MSN). Responses are generally opposite in direction, with the exception of the anterior caudate-putamen and globus pallidus external (GPe). Modified with permission from Lee et al. (2016).

approach. In addition, through computational modeling of the ofMRI data (Bernal-Casas et al., 2017), we parameterized dynamic functional relationship with cell type specificity across the whole brain. A D1-MSN stimulation of ofMRI data with computational modeling showed clear direct pathway signaling, whereas D2-MSN stimulation of ofMRI data with computational modeling show clear indirect pathway and hyperdirect pathway signaling (Fig. 2).

\section{Modulating arousal regulation circuits for therapy}

Modulation of the forebrain arousal regulation network via the central thalamus

Modulation of circuits underlying forebrain arousal regulation offers unique promise in aiding the recovery of integrative function in a variety of neurological conditions producing impaired consciousness. Recent work has furthered understanding of this potential and provided new insights into the anatomical and physiological specialization of neurons within the central thalamus and their role in influencing network activity across the frontostriatal system (Liu et al., 2015; Baker et al., 2016). These new studies help to further frame a rationale for the use of central thalamic deep brain stimulation (CT-DBS) to support arousal regulation mechanisms in the severely injured brain, an approach that has had limited study to date (Schiff et al., 2007; Adams et al., 2016).
An important role for neurons within the central thalamus in forebrain arousal regulation has been long recognized (Schiff, 2008; Mair et al., 2011). Briefly, these neurons have several unique properties among others within thalamocortical projection systems that support their role in broad activation of long-range corticothalamic and corticostriatopallidal thalamocortical networks (Groenewegen and Berendse, 1994; Llinás et al., 1994; Llinás et al., 1998; Purpura and Schiff, 1997). Neurons within the central thalamus (Jones, 2007) receive the strongest thalamic projection from the brainstem cholinergic and noradrenergic afferents as well as glutamatergic inputs from the brainstem reticular formation. As such, these neurons are under the immediate and almost exclusive (Rovó et al., 2012) control of the classical brainstem "arousal systems." Moreover, their anatomical projections have long suggested two unique aspects of their circuit-level functionality: (1) a broad innervation of the striatum with wide arborization of projections across frontal cortical regions (Groenewegen and Berendse, 1994; Deschenes et al., 1996); and (2) a unique cortical laminar innervation pattern supporting columnar activation without interference in columnar input computations (Llinás et al., 1994, 1998; Larkum et al., 1999; Larkum et al., 2007).

These anatomical and related physiological properties, including specialization of synaptic strength in the striatum (Smith 
A

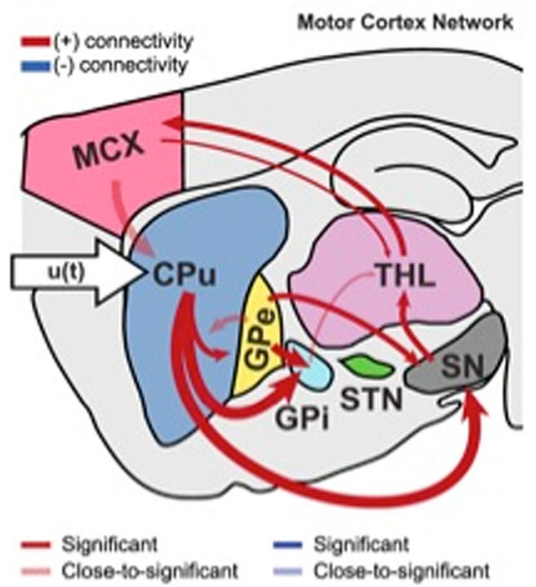

B

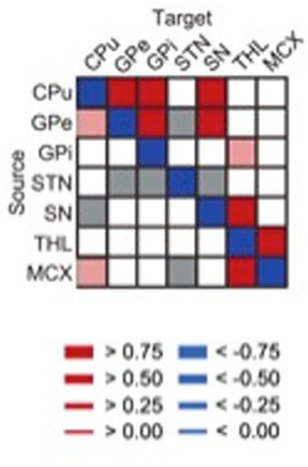

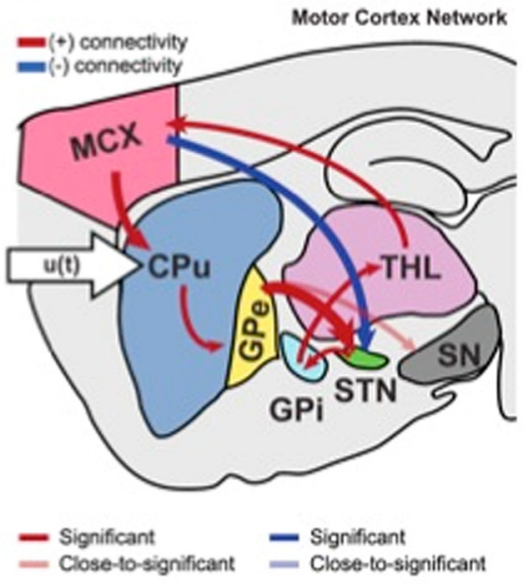



$=0.75=<-0.75$
$=>0.50=<-0.50$
$Z>0.25-<-0.25$
$->0.00-<0.00$

Figure 2. Computational modeling of ofMRI data reveals parameterized dynamic functional relationship with cell type specificity. $\boldsymbol{A}$, D1-MSN stimulation ofMRI data with computational modeling show clear direct pathway signaling. B, D2-MSN stimulation ofMRI data with computational modeling show clear indirect pathway and hyperdirect pathway signaling. Modified with permission from Bernal-Casas et al. (2017).

et al., 2014) and neocortex (Cruikshank et al., 2012), have supported a theory of the organizing role of central thalamic integrity and restoration of an anterior forebrain mesocircuit in recovery following widespread deafferentation produced by multifocal structural brain injuries (Schiff, 2010). This mesocircuit model provides a conceptual foundation for targeting the central thalamus as a privileged node within the forebrain arousal regulation network (Schiff, 2008). A single-subject human study provides proof-of-concept evidence for the CT-DBS approach (Schiff et al., 2007); however, detailed in vivo investigation of circuit modulation arising with CT-DBS across neocortical, striatal, and thalamic populations has only recently come to light. In a pioneering study, Liu et al. (2015) extensively characterized activation of the entire rat brain using optogenetic activation techniques in the central thalamus coupled to fMRI. In these studies, a strong frequency dependence of broad frontal-striatal recruitment was demonstrated with bilateral recruitment appearing with highfrequency stimulation $(100 \mathrm{~Hz})$ of neurons specifically within the central lateral nucleus (Fig. $3 A, B$ ). In addition, this approach reliably produced waking in the rats when asleep.

Complimenting these whole-brain activation patterns, Baker et al. (2016) developed a unique system for electrical stimulation of the central thalamus combining two nearly spaced CT-DBS electrodes to allow comparison of current steering across electrode shafts with single-electrode cathode-anode pairs. In their studies, a robust effect of CT-DBS on behavioral performance appeared with cross-electrode current steering described as "field-shaping" CT-DBS (fSCT-DBS) improving performance. fsCT-DBS produced a maximal impact on performance and anterior forebrain activation when directly compared with conventional CT-DBS; multisite recordings obtained across many frontal cortical and striatal populations demonstrated physiological evidence of enhanced arousal with a dose-dependent effect of current amplitude of fsCT-DBS on cortical and striatal $15-25 \mathrm{~Hz}$ local field potential (LFP) power (Fig. 3C,D) (Baker et al., 2016). These findings show strong concordance with those of Liu et al. (2015), which demonstrated a frequency-dependent increase in activation across the frontal striatal system. Maximal effects on behavioral performance in the nonhuman primate were similarly linked to high-frequency $(>100 \mathrm{~Hz})$ stimulation and activation of both neurons within the central lateral nucleus and within a fiber bundle encompassing the medial aspect of dorsal tegmental tract (Edlow et al., 2012) that carries axons emanating from both the central lateral nucleus and the adjacent centromedianparafascicularis complex.

Together, these recent studies add an important dimension of understanding of the impact of CT-DBS at the circuit level and support the specific role of central thalamic afferents (particularly those of central lateral nucleus) in arousal regulation of the forebrain via graded activation of frontostriatal networks. Direct activation of central lateral thalamic neurons per se appears to have a privileged impact for driving the rostral striatum and frontal cortices. High-frequency stimulation rates of these neuron by either the laser ON optogenetic fiberoptic system or electrical pulses of a DBS system produce broader activation and more robust physiological effects. The findings of Baker et al. (2016) of the preferential effect of activation of the anatomical structure of the medial aspect of dorsal tegmental tract provides a novel and specific target for future translational approaches.

Other clinical applications of modulation of the arousal regulation system via CT-DBS have been proposed; a closely related but distinct approach has been considered by Blumenfeld and colleagues (Gummadavelli et al., 2015; Kundishora et al., 2017) who have pioneered preclinical studies of stimulation of the central lateral thalamus to restore consciousness to rodents during and after seizures during the period of "postictal" unconsciousness. In their studies, electrical stimulation of CL reduced cortical slow waves emerging after electrically induced hippocampal seizures in both anesthetized and awake-behaving rodents. When electrical stimulation was combined with stimulation of the pontine nucleus oralis bilaterally, it could restore consciously mediated behaviors during focal limbic seizures and produce physiological evidence of EEG arousal; unilateral dual-site stimulation, however, could not produce similar behavioral or electrophysiological improvements. Of note, in the Liu et al. (2015) study, absence seizure activity was produced reliably with low-frequency $10 \mathrm{~Hz}$ stimulation in central lateral nucleus supporting the circuit specificity of these effects (see below).

Clinical studies to date have only examined limited aspects of physiological effects of CT-DBS applied to neurons of the central lateral nucleus. Schiff et al. (2007) showed that effective stimulation contacts within this region in their single-subject study produced cortical responses consistent with the classical regional patterns of activation of the forebrain seen with low-frequency 
A

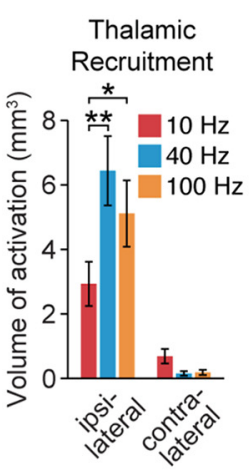

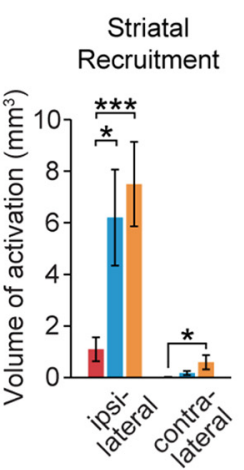

Striatal
Recruitment

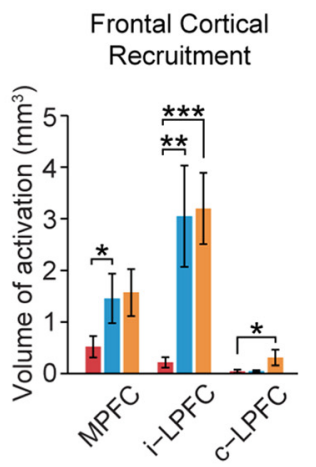

C

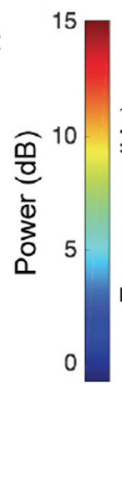

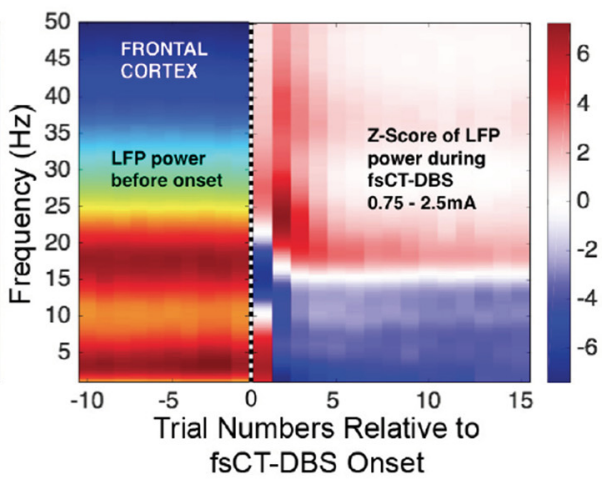

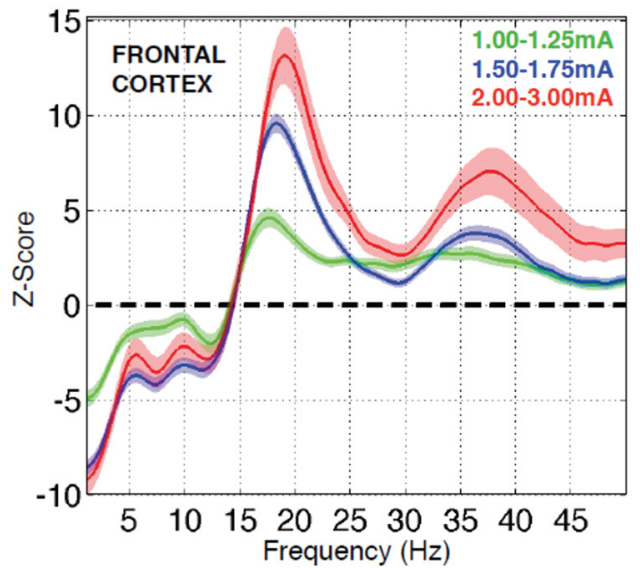

Figure 3. Evidence for dose-dependent effects of activation of frontostriatal networks by high-frequency stimulation of the central lateral nucleus of the thalamus. $A$, Fiberoptic optogenetic activation of central lateral thalamic neurons shows frequency dependence (Liu et al., 2015). ${ }^{*} p<0.05,{ }^{* *} p<0.005,{ }^{* * *} p<0.001$. B, Spatial characterization of evoked fMRI signals showing average coherence maps of brainwide activity during stimulation of excitatory central thalamus relay neurons at $100 \mathrm{~Hz}$. Warm colors represent positive BOLD responses. Cool colors represent negative BOLD responses. MPFC, Medial prefrontal cortex; LPFC, lateral prefrontal cortex; SC, primary somatosensory cortex; Cg, cingulate cortex; Th, thalamus; MC, motor cortex. C, CT-DBS (Baker et al., 2016). Field shaping CT-DBS via cross-electrode stimulation markedly shifts power spectra of LFPs measured across various regions within the frontal cortex and dorsal striatum (data not shown) in the nonhuman primate. Average LFP power (left of vertical dashed line) and average Z score of LFP power (right side of vertical dashed line (for methods, see Baker et al., 2016) concatenated over a series of 10 trials before fsCT-DBS onset, indicated by dashed vertical line at Trial 0 , and 15 trials during fsCT-DBS. LFP activity averaged $>1305$ separate recording sites within the frontal cortex and aggregated $>1325 \mathrm{fsCT-DBS}$ periods conducted in 144 experimental sessions. Stimulation amplitudes ranging from 0.75 to $2.5 \mathrm{~mA}$, and stimulation frequencies of $150,175,200$, and $225 \mathrm{~Hz}$ are included. $\boldsymbol{D}$, Average $Z$ score of the LFP power spectra shown in $\boldsymbol{C}$ but restricted to the delay period of Correct trials during fsCT-DBS 0N periods, relative to the delay period activity of Correct trials recorded during fsCT-DBS 0FF periods, including $95 \%$ CI. Dose-dependent effect of intensity over three sets of stimulation amplitudes, $0.75-1.25,1.50-1.75$, and $2.0-2.5 \mathrm{~mA}$.

activation (the "recruiting response"). EEG modulation in these measurements showed maximal effects over prefrontal and frontal cortical electrodes with some bilateral activation of medial cortical regions. Adams et al. (2016) recently reported on longterm plastic changes in sleep physiology in a separate study of a severely brain-injured human subject over a 5 year period of CTDBS. CT-DBS during the daytime only produced a normalization of sleep architecture and increased frequency of frontal cortical sleep spindles. In the context of the preclinical studies reviewed above, we suggest that CT-DBS can modulate long-term cortical physiology via projections across the frontal-striatal system that support arousal regulation.

Collectively, these clinical and preclinical studies are enlarging our understanding of the forebrain arousal regulation network and its underlying circuit mechanisms. The wide range of investigations that are possible using the full array of physiological and optogenetic approaches show the broad opportunities now available for examining circuit level function in the brain.

\section{ofMRI of central thalamus arousal regulation and} investigation of DBS mechanisms

Although DBS has led to remarkable improvements in patients with neurological disorders ranging from Parkinson's disease to severe depression, the underlying mechanisms remain poorly understood. This lack of mechanistic understanding has prevented DBS from reaching its full therapeutic potential. Our recent study (Liu et al., 2015) shows how we can study DBS and identifies key circuit mechanisms underlying its efficacy.

A key challenge for clinicians and basic scientists alike is understanding the circuit-level mechanisms that link specific DBS parameters to therapeutic benefits. Although it is thought that DBS can do for disorders, such as epilepsy and traumatic brain injury, what it has done for Parkinson's disease, this lack of understanding currently limits the extension of DBS for use in other disorders. A primary obstacle in understanding DBS mechanisms comes from the complex effects of electrical stimulation on mixed populations of neural elements. In many ways, electrical stimulation is a blunt instrument. We addressed this problem by applying ofMRI to selectively target a single, genetically defined population of neurons and reveal a hitherto unknown frequency dependence of CT-DBS. In our studies, we found that lowfrequency stimulation results in robust inhibition of cortex, whereas high-frequency stimulation drives broad activation of striatum and frontal cortex with laminar specificity. The finding that different frequencies of stimulation lead to opposite responses at a remote target (e.g., excitation or inhibition) is highly 


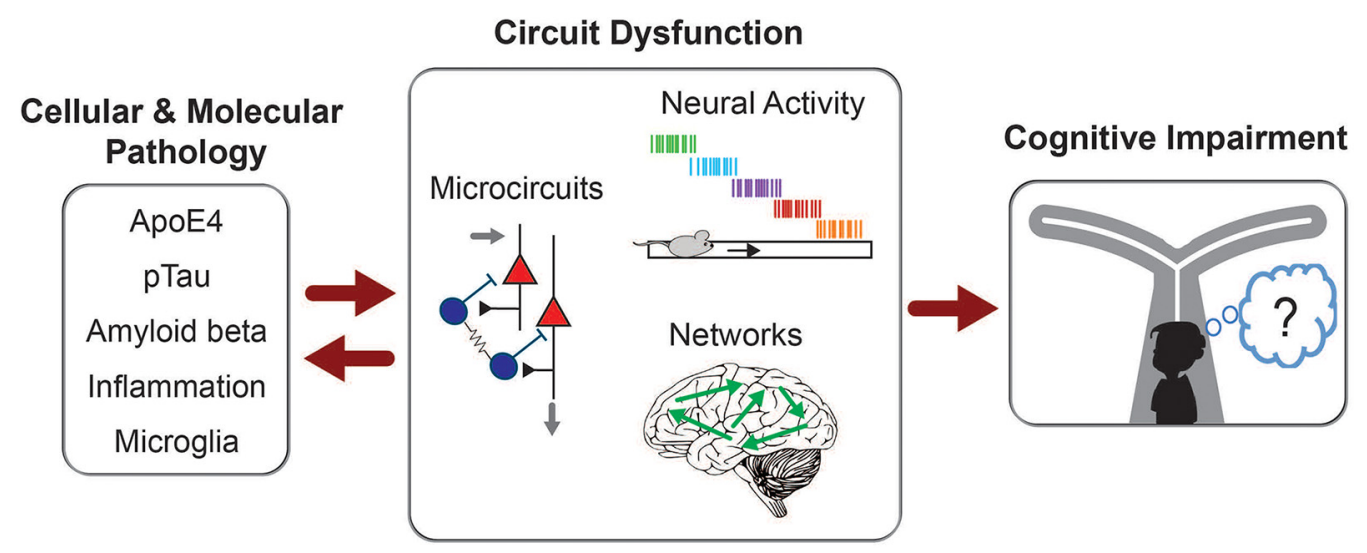

Figure 4. The path from cellular and molecular pathology to cognitive impairment through circuit dysfunction. Multiple molecular and cellular pathologies, including ApoE4, phosphorylate Tau (pTau), amyloid $\beta$, microglia malfunction, and signaling related to inflammation, are thought to contribute to cognitive impairment. How these molecular and cellular pathologies alter circuits to lead to cognitive impairment is not clear and is an active area of investigation, including changes in specific cell types and microcircuits, neural activity during behavior, and large-scale networks.

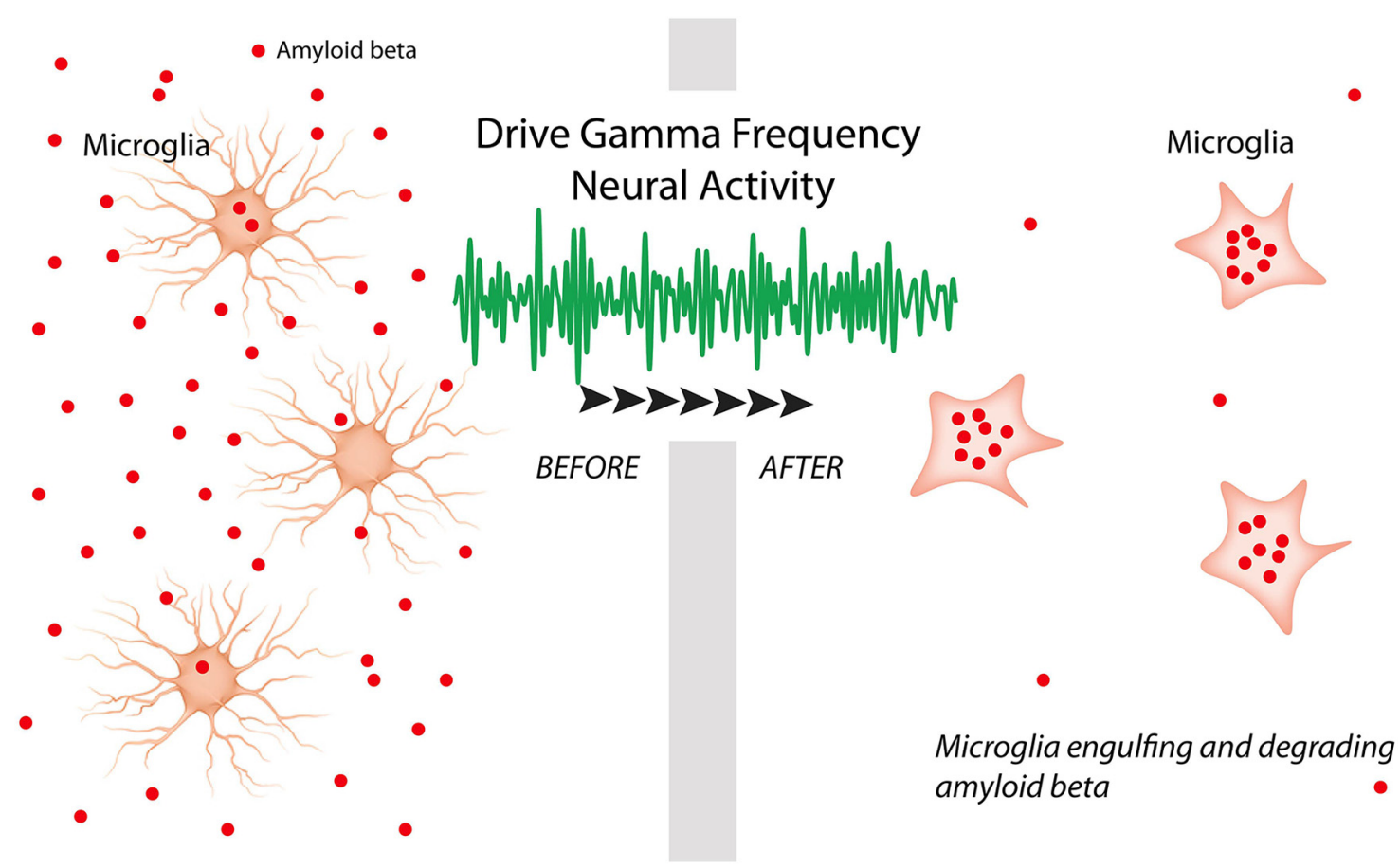

Figure 5. Driving gamma transforms microglia and reduces amyloid. Driving gamma oscillations via optogenetics or noninvasive sensory flicker in mouse models of AD results in reduced amyloid $\beta$ levels and transformed microglia, the primary immune cells in the brain. Following gamma stimulation, microglia's cell bodies become larger, their process length is reduced, and more microglia engulf amyloid $\beta$. Image courtesy of Walter Rich.

surprising and represents a major advance in the understanding of CT-DBS and certainly has immediate implications for the application of DBS clinically. The rich dynamics of our imaging data importantly enabled us to predict the existence of a GABAergic feedback pathway mediated by zona incerta, which we elegantly confirmed through single-unit and field potential electrophysiology techniques.

The results from this study provide a broadly applicable platform for the dissection of DBS mechanisms. Similar methods can be used to dissect the mechanisms of DBS for other neurological disorders (e.g., Parkinson's disease, obsessive compulsive disorder, and depression) and brain regions (e.g., basal ganglia, nucleus accumbens). The combination of targeted optogenetic stimulation with whole-brain fMRI readouts will enable DBS therapies to be individually optimized directly based on their visualized effect on global brain circuits.

\section{Circuit modulation for treating AD}

Neural activity essential for memories of experience

One of the brain areas affected early in the course of AD is the hippocampus, the brain region required for spatial navigation and memories of experience (Squire, 1982; Braak and Braak, 1991; Fox et al., 1996; Dubois et al., 2007) (Fig. 4). Indeed, one of the earliest symptoms of $\mathrm{AD}$ is getting lost in a familiar place (Deipolyi et al., 2007). Decades of research have examined the hippocampus's role in spatial navigation, revealing patterns of neural activity, or neural codes, that represent information about the spatial environment (O'Keefe and Dostrovsky, 1971). Recent 
discoveries have uncovered how these spatial codes drive learning and memory in healthy brains (Carr et al., 2011; Girardeau and Zugaro, 2011). However, we know little about how this activity fails in $\mathrm{AD}$.

Prior research in rodents has established how hippocampal neural activity underlies spatial learning and memory. These studies have revealed that, as an animal explores an environment, pyramidal neurons in the hippocampus fire in specific locations, called place fields (O'Keefe and Dostrovsky, 1971). When an animal runs along a path, the neurons fire in a precise sequence (Dragoi and Buzsáki, 2006). During pauses in behavior and during rest after the behavior is complete, these same sequences are replayed repeatedly on the short timescales required for synaptic plasticity (Skaggs and McNaughton, 1996; Foster and Wilson, 2006; Carr et al., 2011; Girardeau and Zugaro, 2011). This replay occurs during sharp wave ripples (SWRs), high-frequency events detected in the LFP, and is often called SWR replay or reactivation. SWR replay plays a crucial role in spatial learning and memory: if SWRs are disrupted, animals perform significantly worse in spatial memory tasks (Jadhav et al., 2012). Because SWRs repeat sequences of activity many times after the behavior is complete, they are well suited to drive synaptic plasticity between cells in the sequence and for linking those sequences to behavioral outcomes, such as reward (Singer and Frank, 2009). SWRs can also "preplay" future paths when an animal must choose a path to a reward. A lack of this activity predicts incorrect path choice, suggesting that SWRs are important for planning future paths (Singer et al., 2013). During SWR replay, spiking is clocked by gamma oscillations, $20-50 \mathrm{~Hz}$ LFP rhythms present in many brain regions (Carr et al., 2012). Gamma oscillations are produced by synchronized rhythmic inhibition of pyramidal cells by fast spiking parvalbumin (PV)-positive GABAergic interneurons (Cardin et al., 2009; Sohal et al., 2009). Thus, SWR replay results from interactions between PV interneurons and pyramidal cells. Importantly, SWRs are preserved across species, including mice, rats, nonhuman primates, and humans; therefore, SWR deficits discovered in animal models may extend to humans (Buzsáki et al., 2003; Clemens et al., 2007; Logothetis et al., 2012).

\section{Neural activity deficits in mouse models of $\mathrm{AD}$}

Recently, we have discovered that 5XFAD mice have deficits in SWR activity early in disease progression before plaque buildup or evidence of behavioral impairment (Iaccarino et al., 2016). We have identified deficits in the number of SWRs per time, in the strength of gamma oscillations during SWRs, and in how well spikes are modulated by gamma oscillations during SWRs (Iaccarino et al., 2016). These SWR deficits are strikingly similar to those found in older APOE4 mice, even though these two models have very different molecular pathology (Gillespie et al., 2016). The 5XFAD transgenic mouse is a well-established model of AD that carries five familial $\mathrm{AD}$ mutations, whereas the APOE4 knock-in mouse expresses the human apolipoprotein (apo) E4 allele, the main genetic risk factor for $\mathrm{AD}$, in place of the mouse allele (Ramaswamy et al., 2005; Oakley et al., 2006). Furthermore, the deficits we find in 5XFAD mice have some similarities to deficits reported in another mouse model, hAPP, and in humans with AD (Stam et al., 2002; Verret et al., 2012). These results show that SWRs and gamma are altered in multiple AD models, suggesting that the cells and circuits that produce this activity may be especially susceptible to AD pathology. Importantly, SWRs are essential for spatial learning and memory in healthy animals; therefore, these deficits may be a mechanism by which molecular pathology leads to cognitive deficits.

\section{Driving neural activity affects molecular pathology}

Once basic research has established what activity and circuits fail in AD models, new methods to rescue this activity can be tested as potential therapies. Our research has revealed that gamma oscillations are not only altered in $\mathrm{AD}$, but also that stimulating neurons to produce gamma oscillations ("drive gamma") mobilized the immune system to remove amyloid $\beta$, a protein whose aggregation is thought to initiate neurotoxic events (Fig. 5). Specifically, driving gamma recruited the primary immune cells of the brain, microglia, to alter their morphology and increase engulfment of $\beta$ amyloid (Iaccarino et al., 2016). Driving gamma for $1 \mathrm{~h}$ resulted in a $40 \%$ reduction in $\beta$ amyloid. We found consistent reduction in amyloid and recruitment of microglia in multiple brain regions (hippocampus and visual cortex) using multiple methods to drive gamma. In hippocampus, we used optogenetic stimulation of PV interneurons at $40 \mathrm{~Hz}$ to drive gamma oscillations (Cardin et al., 2009). We then developed a method to drive gamma noninvasively in visual brain areas: flickering lights at gamma frequency, like a rapid strobe light. This simple noninvasive manipulation can be readily applied to further examine the effects of driving gamma oscillation. This discovery reveals a surprising effect of neural activity on the brain's immune system and protein accumulation. These results suggest that deficits in neural activity may not only drive learning and memory deficits but also contribute to the molecular and cellular pathology of the disease. As a result, driving specific patterns of neural activity may be able to impact the disease at the cognitive, cellular, and molecular levels.

\section{References}

Adams ZM, Forgacs PB, Conte MM, Nauvel TJ, Drover JD, Schiff ND (2016) Late and progressive alterations of sleep dynamics following central thalamic deep brain stimulation (CT-DBS) in chronic minimally conscious state. Clin Neurophysiol 127:3086-3092. CrossRef Medline

Albin RL, Young AB, Penney JB (1989) The functional anatomy of basal ganglia disorders. Trends Neurosci 12:366-375. CrossRef Medline

Baker JL, Ryou JW, Wei XF, Butson CR, Schiff ND, Purpura KP (2016) Robust modulation of arousal regulation, performance, and frontostriatal activity through central thalamic deep brain stimulation in healthy nonhuman primates. J Neurophysiol 116:2383-2404. CrossRef Medline

Bernal-Casas D, Lee HJ, Weitz AJ, Lee JH (2017) Studying brain circuit function with dynamic causal modeling for optogenetic fMRI. Neuron 93:522-532.e5. CrossRef Medline

Bolam JP, Hanley JJ, Booth PA, Bevan MD (2000) Synaptic organisation of the basal ganglia. J Anat 196:527-542. CrossRef Medline

Braak H, Braak E (1991) Neuropathological staging of Alzheimer-related changes. Acta Neuropathol 82:239-259. CrossRef Medline

Buzsáki G, Buhl DL, Harris KD, Csicsvari J, Czéh B, Morozov A (2003) Hippocampal network patterns of activity in the mouse. Neuroscience 116:201-211. CrossRef Medline

Cardin JA, Carlén M, Meletis K, Knoblich U, Zhang F, Deisseroth K, Tsai LH, Moore CI (2009) Driving fast-spiking cells induces gamma rhythm and controls sensory responses. Nature 459:663-667. CrossRef Medline

Carr MF, Jadhav SP, Frank LM (2011) Hippocampal replay in the awake state: a potential substrate for memory consolidation and retrieval. Nat Neurosci 14:147-153. CrossRef Medline

Carr MF, Karlsson MP, Frank LM (2012) Transient slow gamma synchrony underlies hippocampal memory replay. Neuron 75:700-713. CrossRef Medline

Clemens Z, Mölle M, Eross L, Barsi P, Halász P, Born J (2007) Temporal coupling of parahippocampal ripples, sleep spindles and slow oscillations in humans. Brain 130:2868-2878. CrossRef Medline

Cruikshank SJ, Ahmed OJ, Stevens TR, Patrick SL, Gonzalez AN, Elmaleh M, Connors BW (2012) Thalamic control of layer 1 circuits in prefrontal cortex. J Neurosci 32:17813-17823. CrossRef Medline 
Cui G, Jun SB, Jin X, Pham MD, Vogel SS, Lovinger DM, Costa RM (2013) Concurrent activation of striatal direct and indirect pathways during action initiation. Nature 494:238-242. CrossRef Medline

Deipolyi AR, Rankin KP, Mucke L, Miller BL, Gorno-Tempini ML (2007) Spatial cognition and the human navigation network in AD and MCI. Neurology 69:986-997. CrossRef Medline

DeLong MR (1990) Primate models of movement disorders of basal ganglia origin. Trends Neurosci 13:281-285. CrossRef Medline

Deschenes M, Bourassa J, Parent A (1996) Striatal and cortical projections of single neurons from the central lateral thalamic nucleus in the rat. Neuroscience 72:679-687. CrossRef Medline

Desmurget M, Turner RS (2010) Motor sequences and the basal ganglia: kinematics, not habits. J Neurosci 30:7685-7690. CrossRef Medline

Drago J, Padungchaichot P, Wong JY, Lawrence AJ, McManus JF, Sumarsono SH, Natoli AL, Lakso M, Wreford N, Westphal H, Kola I, Finkelstein DI (1998) Targeted expression of a toxin gene to D1 dopamine receptor neurons by cre-mediated site-specific recombination. J Neurosci 18: 9845-9857. Medline

Dragoi G, Buzsáki G (2006) Temporal encoding of place sequences by hippocampal cell assemblies. Neuron 50:145-157. CrossRef Medline

Dubois B, Feldman HH, Jacova C, Dekosky ST, Barberger-Gateau P, Cummings J, Delacourte A, Galasko D, Gauthier S, Jicha G, Meguro K, O’Brien J, Pasquier F, Robert P, Rossor M, Salloway S, Stern Y, Visser PJ, Scheltens P (2007) Research criteria for the diagnosis of Alzheimer's disease: revising the NINCDS-ADRDA criteria. Lancet Neurol 6:734-746. CrossRef Medline

Dudman JT, Krakauer JW (2016) The basal ganglia: from motor commands to the control of vigor. Curr Opin Neurobiol 37:158-166. CrossRef Medline

Duffy BA, Choy M, Chuapoco MR, Madsen M, Lee JH (2015) MRI compatible optrodes for simultaneous LFP and optogenetic fMRI investigation of seizure-like afterdischarges. Neuroimage 123:173-184. CrossRef Medline

Durieux PF, Bearzatto B, Guiducci S, Buch T, Waisman A, Zoli M, Schiffmann SN, de Kerchove d'Exaerde A (2009) D2R striatopallidal neurons inhibit both locomotor and drug reward processes. Nat Neurosci 12:393395. CrossRef Medline

Edlow BL, Takahashi E, Wu O, Benner T, Dai G, Bu L, Grant PE, Greer DM, Greenberg SM, Kinney HC, Folkerth RD (2012) Neuroanatomic connectivity of the human ascending arousal system critical to consciousness and its disorders. J Neuropathol Exp Neurol 71:531-546. CrossRef Medline

Fang Z, Lee JH (2013) High-throughput optogenetic functional magnetic resonance imaging with parallel computations. J Neurosci Methods 218: 184-195. CrossRef Medline

Fang Z, Van Le N, Choy M, Lee JH (2016) High spatial resolution compressed sensing (HSPARSE) functional MRI. Magn Reson Med 76:440455. CrossRef Medline

Foster DJ, Wilson MA (2006) Reverse replay of behavioural sequences in hippocampal place cells during the awake state. Nature 440:680-683. CrossRef Medline

Fox NC, Warrington EK, Freeborough PA, Hartikainen P, Kennedy AM, Stevens JM, Rossor MN (1996) Presymptomatic hippocampal atrophy in Alzheimer's disease: a longitudinal MRI study. Brain 119:2001-2007. CrossRef Medline

Gillespie AK, Jones EA, Lin YH, Karlsson MP, Kay K, Yoon SY, Tong LM, Nova P, Carr JS, Frank LM, Huang Y (2016) Apolipoprotein E4 causes age-dependent disruption of slow gamma oscillations during hippocampal sharp-wave ripples. Neuron 90:740-751. CrossRef Medline

Girardeau G, Zugaro M (2011) Hippocampal ripples and memory consolidation. Curr Opin Neurobiol 21:452-459. CrossRef Medline

Groenewegen HJ, Berendse HW (1994) The specificity of the 'nonspecific' midline and intralaminar thalamic nuclei. Trends Neurosci 17:52-57. CrossRef Medline

Gummadavelli A, Motelow JE, Smith N, Zhan Q, Schiff ND, Blumenfeld H (2015) Thalamic stimulation to improve level of consciousness after seizures: evaluation of electrophysiology and behavior. Epilepsia 56:114124. CrossRef Medline

Hikida T, Kimura K, Wada N, Funabiki K, Nakanishi S (2010) Distinct roles of synaptic transmission in direct and indirect striatal pathways to reward and aversive behavior. Neuron 66:896-907. CrossRef Medline

Hikosaka O, Kim HF, Yasuda M, Yamamoto S (2014) Basal ganglia circuits for reward value-guided behavior. Annu Rev Neurosci 37:289-306. CrossRef Medline
Iaccarino HF, Singer AC, Martorell AJ, Rudenko A, Gao F, Gillingham TZ, Mathys H, Seo J, Kritskiy O, Abdurrob F, Adaikkan C, Canter RG, Rueda R, Brown EN, Boyden ES, Tsai LH (2016) Gamma frequency entrainment attenuates amyloid load and modifies microglia. Nature 540:230235. CrossRef Medline

Isomura Y, Takekawa T, Harukuni R, Handa T, Aizawa H, Takada M, Fukai T (2013) Reward-modulated motor information in identified striatum neurons. J Neurosci 33:10209-10220. CrossRef Medline

Ito M, Doya K (2011) Multiple representations and algorithms for reinforcement learning in the cortico-basal ganglia circuit. Curr Opin Neurobiol 21:368-373. CrossRef Medline

Jadhav SP, Kemere C, German PW, Frank LM (2012) Awake hippocampal sharp-wave ripples support spatial memory. Science 336:1454-1458. CrossRef Medline

Jones EG (2007) The thalamus, Ed 2. Cambridge, UK: Cambridge UP.

Klaus A, Martins GJ, Paixao VB, Zhou P, Paninski L, Costa RM (2017) The spatiotemporal organization of the striatum encodes action space. Neuron 95:1171-1180.e7. CrossRef Medline

Kravitz AV, Freeze BS, Parker PR, Kay K, Thwin MT, Deisseroth K, Kreitzer AC (2010) Regulation of parkinsonian motor behaviours by optogenetic control of basal ganglia circuitry. Nature 466:622-626. CrossRef Medline

Kundishora AJ, Gummadavelli A, Ma C, Liu M, McCafferty C, Schiff ND, Willie JT, Gross RE, Gerrard J, Blumenfeld H (2017) Restoring conscious arousal during focal limbic seizures with deep brain stimulation. Cereb Cortex 27:1964-1975. CrossRef Medline

Larkum ME, Zhu JJ, Sakmann B (1999) A new cellular mechanism for coupling inputs arriving at different cortical layers. Nature 398:338-341. CrossRef Medline

Larkum ME, Waters J, Sakmann B, Helmchen F (2007) Dendritic spikes in apical dendrites of neocortical layer $2 / 3$ pyramidal neurons. J Neurosci 27:8999-9008. CrossRef Medline

Lee HJ, Weitz AJ, Bernal-Casas D, Duffy BA, Choy M, Kravitz AV, Kreitzer AC, Lee JH (2016) Activation of direct and indirect pathway medium spiny neurons drives distinct brain-wide responses. Neuron 91:412-424. CrossRef Medline

Lee JH, Durand R, Gradinaru V, Zhang F, Goshen I, Kim DS, Fenno LE, Ramakrishnan C, Deisseroth K (2010) Global and local fMRI signals driven by neurons defined optogenetically by type and wiring. Nature 465:788-792. CrossRef Medline

Liu J, Lee HJ, Weitz AJ, Fang Z, Lin P, Choy M, Fisher R, Pinskiy V, Tolpygo A, Mitra P, Schiff N, Lee JH (2015) Frequency-selective control of cortical and subcortical networks by central thalamus. Elife 4:e09215. CrossRef Medline

Llinás R, Ribary U, Joliot M, Wang XJ (1994) Content and context in temporal thalamocortical binding. Heidelberg: Springer.

Llinás R, Ribary U, Contreras D, Pedroarena C (1998) The neuronal basis for consciousness. Philos Trans R Soc Lond B Biol Sci 353:1841-1849. CrossRef Medline

Logothetis NK, Eschenko O, Murayama Y, Augath M, Steudel T, Evrard HC, Besserve M, Oeltermann A (2012) Hippocampal-cortical interaction during periods of subcortical silence. Nature 491:547-553. CrossRef Medline

Mair RG, Onos KD, Hembrook JR (2011) Cognitive activation by central thalamic stimulation: the Yerkes-Dodson law revisited. Dose Response 9:313-331. CrossRef Medline

Oakley H, Cole SL, Logan S, Maus E, Shao P, Craft J, Guillozet-Bongaarts A, Ohno M, Disterhoft J, Van Eldik L, Berry R, Vassar R (2006) Intraneuronal beta-amyloid aggregates, neurodegeneration, and neuron loss in transgenic mice with five familial Alzheimer's disease mutations: potential factors in amyloid plaque formation. J Neurosci 26:10129-10140. CrossRef Medline

O'Keefe J, Dostrovsky J (1971) The hippocampus as a spatial map: preliminary evidence from unit activity in the freely-moving rat. Brain Res 34: 171-175. CrossRef Medline

Purpura KP, Schiff ND (1997) The intralaminar nuclei: a role in visual awareness. Neuroscientist 3:8-15. CrossRef

Ramaswamy G, Xu Q, Huang Y, Weisgraber KH (2005) Effect of domain interaction on apolipoprotein E levels in mouse brain. J Neurosci 25: 10658-10663. CrossRef Medline

Redgrave P, Prescott TJ, Gurney K (1999) The basal ganglia: a vertebrate solution to the selection problem? Neuroscience 89:1009-1023. CrossRef Medline

Roseberry TK, Lee AM, Lalive AL, Wilbrecht L, Bonci A, Kreitzer AC (2016) 
Cell-type-specific control of brainstem locomotor circuits by basal ganglia. Cell 164:526-537. CrossRef Medline

Rovó Z, Ulbert I, Acsády L (2012) Drivers of the primate thalamus. J Neurosci 32:17894-17908. CrossRef Medline

Sano H, Yasoshima Y, Matsushita N, Kaneko T, Kohno K, Pastan I, Kobayashi K (2003) Conditional ablation of striatal neuronal types containing dopamine D2 receptor disturbs coordination of basal ganglia function. J Neurosci 23:9078-9088. Medline

Schiff ND (2008) Central thalamic contributions to arousal regulation and neurological disorders of consciousness. Ann N Y Acad Sci 1129:105-118. CrossRef Medline

Schiff ND (2010) Recovery of consciousness after brain injury: a mesocircuit hypothesis. Trends Neurosci 33:1-9. CrossRef Medline

Schiff ND, Giacino JT, Kalmar K, Victor JD, Baker K, Gerber M, Fritz B, Eisenberg B, Biondi T, O'Connor J, Kobylarz EJ, Farris S, Machado A, McCagg C, Plum F, Fins JJ, Rezai AR (2007) Behavioural improvements with thalamic stimulation after severe traumatic brain injury. Nature 448: 600-603. CrossRef Medline

Singer AC, Frank LM (2009) Rewarded outcomes enhance reactivation of experience in the hippocampus. Neuron 64:910-921. CrossRef Medline

Singer AC, Carr MF, Karlsson MP, Frank LM (2013) Hippocampal SWR activity predicts correct decisions during the initial learning of an alternation task. Neuron 77:1163-1173. CrossRef Medline
Skaggs WE, McNaughton BL (1996) Replay of neuronal firing sequences in rat hippocampus during sleep following spatial experience. Science 271: 1870-1873. CrossRef Medline

Smith Y, Bevan MD, Shink E, Bolam JP (1998) Microcircuitry of the direct and indirect pathways of the basal ganglia. Neuroscience 86:353-387. CrossRef Medline

Smith Y, Galvan A, Ellender TJ, Doig N, Villalba RM, Huerta-Ocampo I, Wichmann T, Bolam JP (2014) The thalamostriatal system in normal and diseased states. Front Syst Neurosci 8:5. CrossRef Medline

Sohal VS, Zhang F, Yizhar O, Deisseroth K (2009) Parvalbumin neurons and gamma rhythms enhance cortical circuit performance. Nature 459: 698-702. CrossRef Medline

Squire LR (1982) The neuropsychology of human memory. Annu Rev Neurosci 5:241-273. CrossRef Medline

Stam CJ, van Cappellen van Walsum AM, Pijnenburg YA, Berendse HW, de Munck JC, Scheltens P, van Dijk BW (2002) Generalized synchronization of MEG recordings in Alzheimer's disease: evidence for involvement of the gamma band. J Clin Neurophysiol 19:562-574. CrossRef Medline

Verret L, Mann EO, Hang GB, Barth AM, Cobos I, Ho K, Devidze N, Masliah E, Kreitzer AC, Mody I, Mucke L, Palop JJ (2012) Inhibitory interneuron deficit links altered network activity and cognitive dysfunction in Alzheimer model. Cell 149:708-721. CrossRef Medline 